This is an unpublished preprint. Please cite as: Verver, H., van Zelst, M., Lucas, G. J. M., \& Meeus, M. T. H. (2019). Understanding Heterogeneity in the Performance Feedback Organizational Responsiveness Relationship: A Meta-Analysis. Preprint retrieved from https://osf.io/hq4uw

\title{
Understanding Heterogeneity in the Performance Feedback - Organizational Responsiveness Relationship: A Meta-Analysis
}

\author{
Hugo Verver* \\ Tilburg University; Department of Organization Studies \\ Marino van Zelst* \\ Tilburg University; Department of Organization Studies
}

Gerardus JM Lucas

Nottingham University Business School; Strategy and International Business division

Marius T.H. Meeus

Tilburg University; Department of Organization Studies

*First two authors contributed equally and are listed in alphabetical order.

Under revision (second round) at Journal of Management

Corresponding author: Hugo Verver, Tilburg University, Department of Organization Studies, PO Box 90153, 5000 LE Tilburg, The Netherlands.Email: h.verver@tilburguniversity.edu 


\begin{abstract}
Organizational performance feedback theory (PFT), which is derived from the Behavioral Theory of the Firm, has emerged as a key perspective guiding studies investigating how performance relative to aspiration levels (i.e., performance feedback) influences organizational responsiveness. While the PFT literature refers to a core prediction - performance below aspirations induces more responsiveness than performance above aspirations does - empirical evidence reveals considerable conflicting findings. In line with contested issues in the current PFT literature, we propose a series of research questions and more refined predictions, which we elated to specific dimensions of performance feedback (valence, type of aspiration level and performance indicator), type of responsiveness (search versus change), and organizational characteristics (age, form of ownership, and industry). We test these refinements with various meta-analytic approaches, based on 263 effect sizes extracted from 156 studies. Our results demonstrate that the way in which performance feedback influences organizational responsiveness is sensitive to the factors we based our predictions on, with meta-analyzed effect sizes ranging from -0.106 to 0.055 . Our findings help to systematically distinguish patterns in the heterogeneity associated with the performance feedbackresponsiveness relationship. These results support our contention that more refined explanations, measures, and models of organizational performance feedback are needed.
\end{abstract}

\title{
Keywords: Meta-Analysis, Performance Feedback, Behavioral Theory of the Firm,
}

Aspirations, Behavioral Strategy 


\section{UNDERSTANDING HETEROGENEITY IN THE PERFORMANCE FEEDBACK - ORGANIZATIONAL RESPONSIVENESS RELATIONSHIP: A META-ANALYSIS}

Why and how organizations adapt over time is a central theme in strategy research (Argote \& Greve, 2007; Bromiley, 1991; Cyert \& March, 1963; Gavetti, Greve, Levinthal, \& Ocasio, 2012; Greve, 1998, 2003b). Organizational performance feedback theory (PFT) - one of the main theories that evolved out of A Behavioral Theory of the Firm (Cyert \& March, 1963) proposes an approach to study organizational adaptiveness that gained prominence in the last decades $^{1}$, but also has become contested recently (Posen, Keil, Kim, \& Meissner, 2018).

PFT claims that organizational responsiveness is affected by performance relative to aspiration levels, or simply 'performance feedback' (Greve, 2003b; Sengul \& Obloj, 2017). PFT offers a common baseline model in which the core prediction hinges on performance feedback valence: performance below aspiration levels (i.e., negative performance feedback) induces greater organizational responsiveness than performance above aspiration levels (i.e., positive performance feedback) does (Cyert \& March, 1963; Greve, 2003a). However, recent empirical studies and narrative reviews reveal that the relationship between organizational responsiveness and performance feedback is more heterogeneous than the core prediction suggests (Klingebiel, 2017; Posen et al., 2018; Shinkle, 2012). In this paper, we propose a number of refinements to this core prediction that follow from a detailed consideration of contested issues in research on PFT pertaining to various dimensions of foundational constructs, measures, and models.

The first contested issue pertains to the tenability of the core prediction, which builds on satisficing behavior. Satisficing behavior entails that negative performance feedback requires action to achieve one's aspiration, whereas positive performance feedback is deemed satisfactory and thus does not (Cyert \& March, 1963; Gavetti et al., 2012). Yet, empirical evidence 
contradicts this core prediction, which indicates that the theoretical explanation of satisficing behavior needs to be revisited and elaborated. With respect to this tenability issue, we specifically explore how the valence dimension of performance feedback, whether performance is below or above an aspiration level, affects organizational responsiveness.

A second contested issue in research on PFT, related to the first issue, pertains to the generic nature of its predictions. At present, PFT assumes that performance feedback of any type using any sort of performance indicator relates in the exact same way to any kind of organizational responsiveness, despite empirical evidence pointing to the contrary. Even though the majority of PFT research considers independent effects of performance relative to distinct historical and social aspiration levels, the predicted effects on organizational responsiveness are identical (Greve, 1998; Kim, Finkelstein, \& Haleblian, 2015). Moreover, PFT research does not differentiate between predicted effects of performance feedback based on financial versus nonfinancial performance indicators. Taken together, this calls for further exploration to resolve the issue whether predictions of PFT are too generic and ignore these dimensions of performance feedback too much. Therefore, we unravel how performance feedback based on the type of aspiration level and distinct performance indicators affects organizational responsiveness.

The third contested issue concerns the divergence in how organizational responsiveness is conceptualized in the PFT literature. Some researchers focus on search (e.g., R\&D intensity (Chen \& Miller, 2007)), which is the generation of solutions that potentially correct or adapt the current set of organizational activities, while others address change (e.g., factory expansion (Audia \& Greve, 2006)), which is the implementation of one or more chosen solutions that potentially correct or adapt the current set of organizational activities (Greve 2003a, 2003b; Posen et al., 2018). Both types of responsiveness differ substantially in for instance the time- 
leggedness relative to the performance feedback and the direct organizational impact they each have. Therefore, we question to what extent the effect of performance feedback on organizational responsiveness is different for search versus change.

Finally, the most common solution to disambiguate conflicting findings and resolve theoretical contestation is to refine a theory by including boundary conditions that specify under what conditions the theory holds or facilitates modified predictions. Therefore, we develop and test predictions for several boundary conditions, which consider that the meaning and importance of performance feedback and the way in which it is translated into action can differ between organizations. We account for organizational characteristics that constrain or enable how organizations process performance feedback and the level of managerial agency in responding to performance feedback: the age of an organization (Desai, 2008), the form of ownership (Greve, 2003b), and the industry the organization operates in (Lant, 1992).

We explore each of these contested issues in research on PFT by analyzing the accumulated evidence (263 effect sizes from 156 studies) on the performance feedbackresponsiveness relationship by applying meta-analytic structural equation modeling (MASEM) and meta-analytic regression analyses (MARA). We are the first to offer an up-to-date quantitative review of PFT and design our meta-analysis in such a way that we can detect both the heterogeneity in findings and determine which of the refinements to PFT we propose, addressing the contested issues identified above, are supported by the accumulated empirical evidence. This allows us to account for systematic patterns in the heterogeneity in findings over and above the core prediction of PFT.

Relative to single studies and narrative reviews, a meta-analytical approach offers significant theoretical and modeling advantages. Since individual studies generally consider a 
subset of the aforementioned dimensions of performance feedback, type of responsiveness, and organizational characteristics, an encompassing perspective on the performance feedbackresponsiveness relationship does not readily emerge. Furthermore, by aggregating this body of empirical work, we can distill a series of patterns by offering statistical estimates on the strength of evidence, whilst controlling for relevant differences between single studies (Combs, Ketchen, Crook, \& Roth, 2011). By considering how various dimensions of performance feedback, the type of organizational responsiveness, and organizational characteristics account for the systematic heterogeneity in empirical findings we pursue a more comprehensive understanding of the effect of performance feedback on organizational responsiveness. This enables us to identify new avenues for research and fruitful extensions to PFT.

\section{THEORY}

Research on performance feedback and aspirations is rooted in the Carnegie tradition, exemplified in work such as Models of Man, Social and Rational by Simon (1957), Organizations by March and Simon (1958) and A Behavioral Theory of the Firm by Cyert and March (1963). Critical of the then prevailing assumptions in the economic theory of the firm, the Carnegie scholars devoted substantial effort to demonstrating the inadequacy of assuming perfect rationality and the benefit of understanding the firm as an organization made up of a variety of units and processes where politics, motivation and other behavioral aspects beyond the conventional input-output function matter. The Carnegie scholars proposed that organizational decision-making occurs under conditions of bounded rationality and ambiguity, resulting in satisficing - decision makers set an aspiration level they try to attain and sequentially evaluate decision alternatives until one is found that meets the aspiration level - being the core decision criterion rather maximization. 
Cyert and March (1963) advanced a theoretical model of how organizational decision makers satisfice (Greve, 2003b). They proposed an explanation that included a set of 'exhaustive variable categories' (goals, expectations and choice), and a set of 'relational concepts' (quasi resolution of conflict, uncertainty avoidance, problemistic search, and organizational learning) that connect the former variables (Cyert \& March, 1963, p. 115). PFT scholars draw on these categories and concepts, but emphasized some over others as well as diverge in conceptual labels and definitions (Argote \& Greve, 2007). In part, this stems from the use of conventional analysis of variance empirical approaches (Posen et al., 2018) whereas Cyert and March (1963) proposed a process theory. Despite the variation in how PFT studies have built on Cyert and March, a number of elements are commonly used in PFT. In this study we use definitions that are common to research on PFT, and for the purpose of clarity we summarize these definitions in Table 1. Insert Table 1 about here

To make effective and efficient decisions despite bounded rationality, decision makers engage in goal setting. They formulate aspiration levels that represent the minimal values for relevant goals that need to be attained in order for performance to be deemed satisfactory. Cyert and March (1963) state that an aspiration level is determined by “the organization's past goal level, the organization's past performance, and the past performance of other "comparable" organizations" (p. 115). Important to note, in the original Cyert \& March (1963) model, performance feedback valence is the driver of responsiveness. Decision-makers compare performance on these goal variables to corresponding aspiration levels (Greve, 1998). In case all aspiration levels are attained, success has been achieved and there is no need for action of any kind per the satisficing criterion. However, if one or more aspiration levels are not attained, this indicates failure and implies the need for action to remedy the performance shortfall. Cyert and 
March (1963) described such action as resulting in choice: decision-makers evaluate decision alternatives and choose the first available one that it is expected to generate performance above the aspiration level. Cyert and March (1963) employed the aforementioned relational concepts to explain such patterns of action resulting in choice. Moreover, PFT has coalesced around explaining two main stages from Cyert and March's (1963) process model (Greve 2003a) as a function of performance feedback: behavior indicative of the search for decision alternatives generally called search - and behavior indicative of the choice to implement particular decision alternatives - generally called change, as unlike search, it involves adjustment of existing practices in the organization ${ }^{2}$.

Having described how the Carnegie scholars laid the groundwork for PFT, we now turn out attention to significant contributions that illustrate major developments in theorizing and modeling in PFT. Lant and colleagues (Lant, Milliken \& Batra, 1992; Lant \& Montgomery, 1987) relaxed Cyert and March's (1963) assumption that responsiveness to performance feedback is a step function driven by performance feedback valence: action, such as search, is started only when performance is below the aspiration level, and not when performance surpasses it. They proposed instead that the degree of responsiveness is monotonically decreasing as performance improves relative to the aspiration level and found evidence to support this proposition (Lant, Milliken \& Batra, 1992; Lant \& Montgomery, 1987). Their proposition also implied that some degree of responsiveness when performance is above the aspiration level was not ruled out in contrast to Cyert \& March's (1963) model, which suggested a dichotomous relationship. Thus, the magnitude of the discrepancy between realized performance and the aspiration level was now considered a determinant of the degree of organizational responsiveness in addition to performance feedback valence. 
Next, Bromiley (1991) introduced the switching model in which organizations pay attention to either an aspiration level that is based on the performance of peers (i.e., social aspiration level) or on their own past performance (i.e., historical aspiration level). He states that organizations pay attention to the social aspiration level until they attain it and then switch their attention to the historical aspiration level. Moreover, organizations will strive to improve on their past performance so set their historical aspiration level at 1.05 times the previous year's. Thus, the switching model (Bromiley, 1991; Wiseman \& Bromiley, 1996) differentiates when organizations would attend to a specific aspiration level, rather than assuming organizations integrate historical and social aspiration levels in an overall one as Cyert \& March (1963) did. Later, Greve $(1998,2003 b)$ incorporated these advances in an updated version of the Cyert and March (1963) model. He proposed a number of further refinements of his own. First, Greve proposed that organizations evaluate performance separately against distinct historical and social aspiration levels. Second, he hypothesized that the relationship between performance feedback and certain types of responsiveness is asymmetrical and not monotonous as Lant and co-authors proposed. Rather, in the kinked curve model Greve $(1998,2003 b)$ formulated, the relationship is discontinuous at the aspiration level such that organizations more quickly reduce their responsiveness once performance surpasses the aspiration level. In his own work Greve (2003a) found the kinked curve model applies to some but not all types of responsiveness. While support for the kinked curve model is variable, the innovation of modelling performance feedback below aspiration levels separately from feedback above aspiration levels (i.e., splined regression analysis) and doing so for performance relative to separate historical and social aspiration levels has allowed researchers to achieve greater explanatory power (Bromiley \& Harris, 2014) than other models such as the switching model (Bromiley, 1991) and the original 
aspiration formula from Cyert and March (1963). Most recent research incorporates these refinements to model the performance feedback- responsiveness relationship and thus we take this 'separate model' to be the baseline for our paper.

Following these three key contributions to PFT, studies using this concept have become greater in number (Argote \& Greve, 2007; Gavetti et al., 2012). These studies have extended and tested performance feedback models in a range of empirical contexts, using different performance indicators, related those to various types of organizational responsiveness and accounted for numerous moderating variables to identify boundary conditions. As such, the literature has gone beyond what Cyert and March (1963) proposed. Some scholars have reviewed and summarized these insights (Klingebiel, 2017; Posen et al., 2018; Shinkle, 2012), which provides a much needed overview of PFT research. Notably, each of these summaries concludes that the field is fragmented as does our own cursory examination of what performance feedbackresponsiveness relationships are encountered in the literature (Appendix 1) $)^{3}$. Thus, it is challenging to see a clear evolution of the Cyert and March (1963) model into a more fullfledged and empirically supported theory as was the intent of the Carnegie scholars. Rather, the aforementioned surveys of the empirical evidence identify a range of findings with no clear consensus on how performance feedback influences organizational responsiveness.

We make two observations based on this general overview of the state of PFT research. First, to a considerable degree, the increasing sophistication in operationalization of key constructs is not accompanied by equal levels of sophistication in theoretical explanation. Posen et al. (2018) identify this clearly where they point out PFT scholars continue to refer to the initial conceptualization derived from Cyert and March (1963) despite accumulation of contradictory evidence. We add to their concerns regarding the status of PFT that such reference at times 
provides a one-sided perspective on, or perhaps even a misrepresentation of, Cyert and March's (1963) contribution. This underscores the motivation for the current meta-analytic review of the body of evidence on PFT. Further below we build on the contested issues, which as we highlighted earlier in the introduction are concerned with achieving much needed theoretical sophistication, in order to address divergence in findings and advance explanations that allow us to distinguish systematic patterns in these divergent findings.

Second, based on this divergence in findings we deduce that performance feedback both enables and constrains organizational responsiveness. In some situations as per the core prediction the satisficing decision criterion applies, while in other situations complementary or even alternative, diverging explanations are needed. The literature (Chen \& Miller, 2007; March \& Shapira, 1993; Miller \& Chen, 2004) proposed switching from attending to the aspiration level to attending to a reference point based on distance to bankruptcy as a complementary explanation when organizations perform well below the aspiration level (Audia \& Greve, 2006). Rather than increased responsiveness as performance declines far below the aspiration level in line with the satisficing decision criterion, organizations would become more conservative and thus less responsive due to the constraints on investing additional resources as they are close to the bankruptcy point.

Furthermore, scholars advanced alternative behavioral and resource based explanations for how performance feedback influences organizational responsiveness. The 'threat rigidity' hypothesis is an example of such a behavioral explanation, and states that organizations react conservatively following negative performance feedback as it threatens their vital interests (Staw, Sandelands, \& Dutton, 1981). An alternative behavioral perspective is the 'capability cue' perspective (Chatterjee \& Hambrick, 2011), which proposes that performance feedback is 
perceived by managers as a signal that validates their competence. Hence, negative (positive) performance feedback decreases (increases) confidence in one's own abilities and discourages (encourages) organizational responsiveness (Buyl \& Boone, 2014; Chatterjee \& Hambrick, 2007). A resource-based explanation is the 'slack-driven' search perspective, which stems from the idea that positive performance feedback, where slack is retained in the organization, leads to experimentation and change because managers can afford to do so, due to their access to additional or lower-cost resources and relaxation of organizational controls (Baum, Rowley, Shipilov, \& Chuang, 2005). These complementary and alternative explanations have been shown to have merit, yet also refer to factors (e.g., slack) which are considered to affect organizational responsiveness directly (Cyert \& March, 1963; Greve, 2003b) rather than constitute part of the process by which performance feedback drives organizational responsiveness. In the following, we explore factors that relate to the main dimensions of performance feedback, type of responsiveness, and to important organizational characteristics affecting how performance feedback is processed and translated into action.

\section{Hypotheses and Research Questions}

Pertaining to the tenability issue of the core prediction, results of previous research indicate that the way performance feedback affects responsiveness is more heterogeneous than the core prediction on satisficing behavior suggests (Klingebiel, 2017; Posen et al., 2018; Shinkle, 2012). For example, Greve (2003a) found that organizations increase R\&D intensity when confronted with negative performance feedback, while Xu, Zhou, and Du (2018) found that organizations decrease R\&D intensity when confronted with negative performance feedback. Because complementary and alternative explanations have been advanced with respect to the valence dimension of performance feedback, and empirical evidence shows they have 
merit, it is not warranted to formulate a hypothesis on the effect of performance feedback valence on organizational responsiveness. Therefore, we can only explore how and to what extent performance feedback valence, whether performance is below or above an aspiration level, affects organizational responsiveness. Thus, we propose the following research question.

Research Question 1: To what extent does performance feedback valence (i.e., negative versus positive performance feedback) affect the strength of the relationship between performance feedback and organizational responsiveness?

A second contested issue concerns the generic nature of PFT predictions, implying that PFT ignores important dimensions of performance feedback. First, PFT does not differentiate between predicted effects of performance relative to distinct historical and social aspiration levels. With one notable exception (Kim et al., 2015), PFT scholars predict similar effects of social and historical performance feedback on responsiveness (e.g., Greve, 1998). Second, PFT thus far has neglected differences between predicted effects of financial and non-financial performance feedback. Rather than assuming performance feedback of any sort relates in the exact same way to any type of organizational responsiveness, empirical findings indicate that we should consider how variation in dimensions of performance feedback bring about systematic differences in the relationship with organizational responsiveness (Kim et al., 2015).

The type of aspiration level, as a dimension of performance feedback, allows for further refinement in theorizing about the effect of performance feedback on organizational responsiveness. Social aspiration levels can become irrelevant if an organization differs to a large extent from other organizations in the same industry (Greve, 2003a). Because information about competitors is harder to evaluate, social performance feedback is more ambiguous (Kim et al., 2015) while information of the organization's past and current performance is readily accessible 
and more straightforward (Greve, 2003b). Therefore, we expect that historical performance feedback influences organizational responsiveness more strongly (Short \& Palmer, 2003) and thus propose the following hypothesis:

Hypothesis 1: Organizations are more responsive to historical performance feedback than to social performance feedback.

The type of performance indicator represents another dimension of performance feedback that potentially affects the performance feedback-responsiveness relationship. The distinction between financial and non-financial performance indicators allows for further nuance as to what organizations deem relevant performance feedback (Venkatraman \& Ramanujam, 1986). The majority of studies on performance feedback make use of financial performance indicators in their modeling efforts (Greve, 2008). This is commonly a general profitability measure such as return on assets (ROA), whereas Cyert \& March (1963) consider profitability only one of a variety of types of goals for which decision-makers would formulate aspiration levels. An important advantage of financial metrics is that they are standardized accounting indicators that facilitate performance comparison. Unfortunately, generic financial performance only informs organizations that there are problems when confronted with negative performance feedback, but does not give any indication of why and where these problems occurred. Therefore, financial performance feedback offers little guidance on the direction or magnitude of responses required. Non-financial performance indicators on the other hand, such as the number of new product introductions (Tyler \& Caner, 2016) or patents (Lungeanu, Stern, \& Zajac, 2016), clearly identify in what organizational area a firm is lagging behind or performs above average. Nonfinancial performance indicators, are often more disaggregated and therefore more readily point to a specific problem area than financial performance indicators of a more generic type (Greve, 
2003b). Therefore, non-financial performance feedback provides more guidance for organizational responsiveness. Hence we hypothesize that:

Hypothesis 2: The type of performance indicator moderates the relationship between performance feedback and organizational responsiveness, such that organizations are more responsive to non-financial performance feedback than to financial performance feedback.

A third issue pertains to whether the effect of performance feedback on organizational responsiveness is different for search versus change. 'Search' pertains to the generation of solutions that potentially correct or adapt the current set of organizational activities, while 'change' pertains to the implementation of one or more solutions that potentially correct or adapt the current set of organizational activities (Cyert \& March, 1963; Greve, 2003a, 2003b; Posen et al., 2018). The background of this concern resides in the fact that studies focusing on the effect of performance feedback on organizational responsiveness have so far investigated over 50 unique types of organizational responsiveness. However, all of these fall within either one of the two main theoretically distinct categories described within the literature on PFT, namely organizational search and change (Cyert \& March, 1963; Greve, 2003a, 2003b; Posen et al., $2018)^{4}$. Our study design allows us to explore how and to what extent the effect of performance feedback on organizational responsiveness is different for search versus change.

Although search and change are interrelated, PFT studies often consider only one type of responsiveness in their theorizing and modeling efforts. It is theoretically relevant to emphasize this interrelationship between search and change as they represent two distinct phases of organizations exploring possible solutions to performance problems and implementing these solutions (Posen et al., 2018). One of the most prevalent search response is to invest resources in R\&D (Chen, 2008; Chen \& Miller, 2007; Greve, 2003a; Lucas, Knoben, \& Meeus, 2018). Based 
on the outcomes of $\mathrm{R} \& \mathrm{D}$, organizations are able to make specific changes such as introducing new and improved products and services (Greve, 2003a; Parker, Krause, \& Covin, 2017).

Cyert and March (1963) not only proposed that search and change are distinct types of responsiveness elicited by performance feedback; they also proposed that search precedes change. Search occurs around the problem area indicated by performance feedback; it serves the role of understanding the reason why performance was unsatisfactory as well as to generate potential solutions to this problem (Greve, 2003b). If this proves difficult, search will expand beyond the problem area into other areas of the organization, a move from local to distant search. Thus search occurs with a shorter time lag after receiving performance feedback than change does. Based on this insight, the case can be made for a stronger influence of performance feedback on search than on change. On the other hand, organizations tend to build up buffers of solutions (Greve, 2003b) that can be utilized when facing low performance. Thus, change can be directly triggered by performance feedback since organization can just implement available solutions rather than first engage in search and only later implement satisfactory solutions found that way. Since the above insights leave it undecided whether performance feedback would more strongly influence search than change or vice versa, we ask the following question:

Research Question 2: To what extent is the effect of performance feedback on search, similar or different to the effect of performance feedback on change?

In theory-driven empirical research, the most common solution to disambiguate and resolve empirical contestation in a theory is to find boundary conditions that help explain the inconsistent findings and elaborate the theoretical arguments. Considering that the meaning and importance of performance feedback and the way in which it is translated into action can differ between organizations, we develop and test predictions for several boundary conditions: the age 
of an organization, the form of ownership, and the industry the organization operates in. We account for these organizational characteristics because these have been previously linked to the prevalence of responsiveness, differences in how organizations process and attend to performance feedback, and to the discretion decision makers have in engaging in responsiveness (Desai, 2008; Shinkle, 2012). In addition to these substantive reasons, these variables are suitable for inclusion in our meta-analysis as these are sufficiently prevalent organizational characteristics in our sample of PFT studies.

Organizational age, the first organizational characteristic we consider, influences the performance feedback-responsiveness relationship because it suppresses responsiveness. Thornhill and Amit (2003) demonstrated that mortality rates among older firms point to an inability to adapt to environmental change. Likewise, Le Mens, Polosz, and Hannan (2015) demonstrate that older firms have relatively more difficulty adapting to changing environments. Audia and Greve (2006) used age as a control variable to assess bureaucracy effects and to indicate obsolescence. They found that older firms expand less than younger firms do, regardless of their performance feedback. With respect to the moderation effect of age on the performance feedback-responsiveness relationship, Desai (2008) derives arguments from a structural inertia perspective. He demonstrates that older organizations are less responsive to negative performance feedback as routines, existing networks, and structures prevail over environmental requirements. Combining these arguments, we formulate the following hypothesis:

Hypothesis 3: Organizational age negatively moderates the relationship between performance feedback and organizational responsiveness, such that older organizations are less responsive to performance feedback than younger organizations. 
The second organizational characteristic we consider is the form of ownership. PFT studies on publicly traded organizations are likely to provide context specific results because these kind of organizations face a legal requirement to report (in standardized formats) extensive details on their performance, strategy, and (intended and executed) organizational responsiveness (Capron \& Shen, 2007; Fitza \& Tihanyi, 2017).. Relative to privately owned firms, information on performance and responsiveness of public organizations is more transparent and accessible (Peteraf, 1993) and thereby comparable. Furthermore, publicly listed organizations have to deal with shareholders that pressure such organizations to act given negative performance feedback (Villagrasa, Buyl, \& Escribá-Esteve, 2017). Shareholders expect these organizations to perform at least on par with other organizations in its reference group, which limits the discretion decision makers have in responding to performance feedback (Blettner, He, Hu, \& Bettis, 2015). Being exposed to such pressure results in an increased propensity of organizational responsiveness to performance feedback. Hence, we arrive at the following hypothesis:

Hypothesis 4: Form of ownership moderates the relationship between performance feedback and organizational responsiveness, such that public organizations are more responsive to performance feedback than private organizations.

The final organizational characteristic we consider is the industry an organization operates in. Specifically, we make the case that organizations in the high tech industry process performance feedback differently from organizations active in the manufacturing and services industries. These industries differ in terms of environmental turbulence: the pace of change as well as the degree of dynamism in the high tech industry is greater than in the latter industries (Nadkarni \& Naranayan, 2007). Contingency Theory scholars have argued that organizations must 'fit' their strategy and structures to the nature of their environment (Donaldson, 1987). We 
propose that fit with the environment also applies to what sort of performance feedback is most useful for an organization to attend to. Specifically, we expect organizations in the high tech industry to face performance feedback that is more volatile, making the historical aspiration level less useful for evaluating performance. A historical aspiration level relies on available information from past performance of one's own organization and is useful for forecasting in a stable environment (Greve, 2003b). However, in turbulent environments environmental changes rapidly render historical performance feedback outdated, because performance itself becomes more volatile, and thus useless. Comparing performance with a social aspiration level, in which salient peers experienced a similar turbulent environment, helps organizations to handle uncertainty in the evaluation of current performance outcomes (Greve, 2003b). Alternatively, organizations can complement historical with social performance feedback (Kim et al., 2015) to assess its reliability. Social performance feedback is therefore believed to be especially relevant during periods of high environmental turbulence and technological changes (Greve, 2003b; Joseph, 2014). Therefore, we propose that:

\section{Hypothesis 5: Organizations are more responsive to social performance feedback} than to historical performance feedback in high tech industries.

\section{METHODS}

We employed four different search procedures to identify studies for inclusion in our meta-analysis that offer empirical tests of performance feedback models. First, we searched the following electronic databases: ISI Web of Knowledge, ABI/INFORM Global and SSRN. We constructed a set of key phrases by combining "performance feedback", “aspiration”, "attainment discrepancy", and "behavioral theory of the firm" with keywords indicating relevant organizational outcome variables: "strategy", “decision”, “change”, “innovation”, “explorative”, "exploitative", "risk", "adaptation", "search", and "learning”. Second, we inspected the reference 
lists of all studies found through the first search method as well as the "cited-by" lists to identify additional studies (i.e., back- and forward snowballing). Third, we manually searched a set of journals that are known to publish studies on $\mathrm{PFT}^{5}$. We also searched in conference proceedings of the Academy of Management and the Social Science Research Network database, to find unpublished work and reduce the "file drawer" problem (Samba, Knippenberg, \& Miller, 2017).

Fourth, we e-mailed all authors of studies with missing data, such as effect sizes, sample sizes, or sample criteria, to request that information. We also enquired whether they had any unpublished work on PFT that they could share with us. The last search/request was conducted/sent in April 2018. In total, we identified 156 manuscripts (1986 - 2018) that studied PFT.

\section{Inclusion Criteria}

We used three inclusion criteria: (1) we only included papers that studied the performance feedback-organizational responsiveness relationship, excluding papers on individual performance feedback and responsiveness, (2) studies had to specify performance feedback by separating historical and social performance feedback and take into account that regression slopes could vary for performance below and above the aspiration level (i.e., use splined regression) since successive advancements to PFT have demonstrated these contrasts are theoretically relevant and result in meaningful empirical differences (Bromiley \& Harris, 2014; Greve, 1998), and (3) studies with a dependent variable operationalized as a ratio variable between two behavioral responses, such as the level of exploration relative to exploitation, are excluded. The correlation coefficient between performance feedback and such ratio variables does not correspond to more or less responsiveness to performance feedback, but rather indicates the type of responsiveness. 
Applying these inclusion criteria yielded a final set of 63 PFT studies to be included in the meta-analysis, covering a time period of 20 years (1998 - 2018). The dataset included 52 journal articles, 0 book chapters, and 11 unpublished manuscripts. A full list of studies from which correlations were extracted and the number of studies per publication outlet are available in an online supplement ${ }^{6}$.

\section{Coding Procedures}

Several steps were taken to ensure the reliable extraction of data from each primary study. The author team prepared a coding protocol to outline the information we required from each study. To refine the protocol, all authors coded 22 papers individually and then jointly discussed discrepancies in coding choices as well as anything not covered by the initial coding scheme until we agreed on the final coding protocol. Subsequently, the first and second author independently coded all studies and discussed all discrepancies until agreement was reached.

The studies that we included in our database present correlation coefficients $(r s)$, which we recorded in our data table along with sample sizes and other sample criteria of these studies. We extracted multiple effect sizes per relationship from each primary study if studies reported multiple effect sizes (e.g., some studies report robustness checks with different performance indicators). We choose to do so because: (1) this gave us the opportunity to assess various boundary conditions on our primary relationships and (2) meta-analyses including multiple effect sizes have been demonstrated to outperform meta-analyses that average effect sizes per study (Bijmolt \& Pieters, 2001). As a robustness check, we performed hierarchical multilevel modeling meta-analysis (HiLMMA) to rule out biased estimates due to stochastic dependencies (Raudenbush \& Bryk, 2002). 
Another potential source of stochastic dependency is the repeated use of datasets by the same authors or through secondary data from large-scale databases (e.g., COMPUSTAT). Some authors used similar datasets in multiple studies to examine a context or research question from multiple angles. When authors used similar datasets for multiple studies, we verified that the operationalization of the relevant variables differed, and whether the effect sizes and sample size differed. We determined that none of the studies in our meta-analytic database are based on the exact same sample, precluding the existence of stochastic dependencies in our data that could result in biased estimators in our results. Finally, we recoded the sign of some effect sizes to ensure consistent interpretation of correlations across the studies included in the analysis.

\section{Variables}

We used two types of organizational responsiveness in this study, search and change. Examples of search are change in R\&D intensity (Lucas et al., 2018) and the number of exploratory projects in clinical trials pipeline (Keil, Kostopoulos, Syrigos, \& Meissner, 2016). Examples of change include entering new markets (Ref \& Shapira, 2017), changes in radio formats (Greve, 1998), and the number of new product introductions (Parker et al., 2017).

Performance feedback is generally operationalized as historical performance feedback and/or social performance feedback. Historical performance feedback is usually calculated by subtracting the performance in year $t_{-2}$ from the performance in year $t_{-1}$. Some studies model the historical aspiration level as a combination of past year's performance and an adaptive component for historical aspirations, which also takes the performance of previous years into account (Greve, 2003a). Social performance feedback is usually calculated by subtracting the mean/median performance of the industry in year $t_{-1}$ from the focal firm's performance in year $t_{-1}$. Some studies have operationalized the reference group more specifically by taking into 
account similarity to other organizations with respect to e.g., size or corporate form (Baum et al., 2005; Greve, 2008).

\section{Meta-analytic Procedures}

As mentioned before, we take the 'separate model' (Greve, 1998) to be the baseline for our analyses. This means that for all analyses we differentiate between the four main dimensions of performance feedback that are associated with the separate model: performance below historical aspiration levels ( $\mathrm{P}<\mathrm{HA})$, performance above historical aspiration levels $(\mathrm{P}>\mathrm{HA})$, performance below social aspiration levels $(\mathrm{P}<\mathrm{SA})$, and performance above social aspiration levels (P > SA). This allowed us to differentiate between effects of performance feedback on organizational responsiveness with respect to performance feedback valence (Research Question 1) as well as the type of aspiration level (historical and social performance feedback) (Hypothesis 1). A total of 263 effect sizes were retrieved for the performance feedbackresponsiveness relationship (i.e., 61 for $\mathrm{P}<\mathrm{HA}, 59$ for $\mathrm{P}>\mathrm{HA}, 71$ for $\mathrm{P}<\mathrm{SA}$, and 72 for $\mathrm{P}>$ SA) from a final sample of 43973 firms for $(\mathrm{P}<\mathrm{HA}), 42320$ firms $(\mathrm{P}>\mathrm{HA}), 54738$ firms $(\mathrm{P}<$ SA), and 53198 firms (P > SA).

We conducted four analyses to quantify the heterogeneity in the four main relationships of interest. First, we estimated Q-statistics since the significance of this statistic is a decision rule for the existence of boundary conditions (Hedges \& Olkin, 2014). Second, we calculated $\tau^{2}$ for each relationship which is an estimate of absolute between-study variance (Gonzalez-Mulé \& Aguinis, 2017). Third, we estimated $80 \%$ credibility intervals around the mean effect sizes for each of the four performance feedback-responsiveness relationships where the lower and upper bounds denote the boundaries of the population effect size (Schmidt \& Hunter, 2014). A credibility interval that contains the zero is indicative of the existence of boundary conditions. 
Finally, we calculated $I^{2}$ for each relationship, which is a relative measure of heterogeneity and can be compared across different meta-analyses (Higgins \& Thompson, 2002). An $I^{2}$ larger than $50 \%$ is generally regarded as a moderate amount of heterogeneity that requires further investigation. Evidence for heterogeneity indicates that the core prediction of PFT needs to be revisited and elaborated.

To test Research Questions 1 and 2, as well as Hypothesis 1 and 5, we used meta-analytic structural equation modeling (MASEM) that uses a two-staged procedure (Bergh et al., 2016). First, we compiled a meta-analytic correlation matrix through separate meta-analyses for each cell of the matrix. We applied the Hedges and Olkin (1985) methodology, which weighs effect sizes by their sample size. We corrected for skewness in the effect size distribution by applying Fisher's z transformations (Geyskens, Krishnan, Steenkamp, \& Cunha, 2009). Random-effects models were used to meta-analyze the effect sizes, as we assumed that the heterogeneity in the effect sizes is substantial which precluded the use of fixed-effects analyses (Geyskens et al., 2009). The DerSimonian-Laird estimator, which is an inverse-variance weighted technique, was used to quantify heterogeneity in the form of $\tau^{2}$ (Viechtbauer, 2005).

Second, we used the meta-analytic correlation matrix as input and subsequently applied structural equation modeling on that matrix. MASEM allows for the inclusion of control variables while simultaneously correcting for dependence amongst predictor variables (Geyskens et al., 2009). We used the generalized least squares estimation because we only specified direct effects (Jak, 2015). Six control variables were included in the specification of the models for the different organizational responses. We controlled for absorbed, unabsorbed, and potential slack as a larger amount of slack resources grants managers greater latitude for experimentation (Chen \& Miller, 2007; Singh, 1986). We controlled for distance to bankruptcy, as the survival reference 
point reduces organizational search and change according to the threat-rigidity hypothesis (Staw et al., 1981). We also incorporated organizational size as larger organizations have a larger and more rigid set of established routines, causing them to be more inert. On the other hand, larger organizations have more resources available to engage in organizational search and change (Shimizu \& Hitt, 2005). Finally, we control for organizational age ${ }^{7}$ as older organizations are more inert and less likely to change the organization (Desai, 2008; Shimizu \& Hitt, 2005). We estimated these path models in R (Version 3.5.0; R Core Team, 2017) using metafor (Version 2.0.0; Viechtbauer, 2010) and lavaan (Version 0.6.3; Rosseel, 2012). We used the harmonic mean as a sample size for the path models, as it is more conservative than the arithmetic mean (Drees \& Heugens, 2013). The average number of firms in the search model is 3532 while for change as a type of responsiveness it is 16341 .

We assessed Research Question 1 in two ways. First, we estimated the explained variance for a model that only included negative performance feedback as well as a model that only included positive performance feedback. Second, we conducted Wald-type tests for differences in parameters in which we compared the slope estimates of negative and positive performance feedback. For Hypothesis 1, we conducted Wald-type tests for difference in parameters in which we compared the slope estimates of performance below historical- and social aspiration levels as well as the slope estimates of performance above historical- and social aspiration levels. To assess Research Question 2, we compared the explained variance for the search and change models. We also conducted Wald-type tests for differences in parameters in which we compared the slope estimates of the search and change models. For Hypothesis 5, we coded the type of industry to distinguish "manufacturing", "high tech", "service", and "other" industry categories (Drees \& Heugens, 2013). We subsequently estimated a MASEM in which we only included 
studies that used data from high tech industries. We tested Hypothesis 5 by conducting Waldtype tests for differences in parameters in which we compared the slope estimates of historical and social performance feedback (similar to Hypothesis 1).

\section{Meta-analytic Regression Analysis}

To test Hypotheses 2, 3 and, 4, we used meta-analytic regression analysis (MARA) (Lipsey \& Wilson, 2001). Within MARA, the predictors are study-level variables and the dependent variable is the effect size. Meta-regression allows for the inclusion of multiple moderators at once, while it "separates the effects of different moderators" (Geyskens et al., 2009 , p. 398). The effect sizes in our model were weighted by their inverse variance to account for differences in precision of the effect sizes. Following best-practice recommendations, we used mixed-effects MARA to quantify the moderating effects of contextual contingencies (Geyskens et al., 2009; Gonzalez-Mulé \& Aguinis, 2017). We estimated all meta-regression analyses with the Knapp and Hartung adjustment (2003), which provides adequate control for Type I error rates (Viechtbauer, López-López, Sánchez-Meca, \& Marín-Martínez, 2015).

We included several moderators to test Hypotheses 2, 3 and 4 to model between-study variance. To test Hypothesis 2, we included a dummy for performance indicator: "non-financial metric" and "financial metric" (reference category). We included organizational age to test Hypothesis 3, measured as the average firm age in the sample of the primary study. We included a dummy for form of ownership to test Hypothesis 4: "private", "mixed", and "public" (reference category). We included two sets of dummy variables to control for substantive factors: (1) industry type: "high-technology", "service", or "manufacturing" (reference category) and (2) type of organizational responsiveness: "change" and "search" (reference category). 


\section{Robustness Checks}

We conducted several robustness checks. First, we included methodological moderators in the MARAs to account for their potential influence: publication status: "published" or "unpublished" (reference category), operationalization of dependent variable: "continuous", "count", or "dichotomous" (reference category), historical aspiration: "performance at $t_{-2}$ " or "multiple years/weighted average" (reference category), social referent group: "industry mean/median" or "specified referent group" (reference category). We ran a robustness check for each moderator separately, as the amount of effect sizes in our sample is fairly small.

Second, we ran hierarchical linear modeling meta-analysis (HiLMMA; Marano, Arregle, Hitt, Spadafora, \& Essen, 2016; Raudenbush \& Bryk, 2002) to rule out the possibility that stochastic dependencies influenced our results. Here, we treated each effect size as a level 1 observation and the study from which it was derived as a level 2 observation. HiLMMA therefore adds a random component to effect sizes that were derived from the same study, recognizing that these effect sizes come from the same sample. We repeated all separate metaanalyses using HiLMMA and repeated the MASEMs for search and change as well as the metaregression analyses ${ }^{8}$.

Third, we collected effect sizes from studies that calculated aspiration levels based on the formula of Cyert and March (1963). We only included studies that used splined regression so we were able to maintain consistency with our main analyses. We compiled correlation matrices for both organizational search and change and reran the MASEMs to assure the validity of the claim that historical and social performance feedback ought to be estimated separately. We also reran the MARAs with these effect sizes and added the $\alpha$ coefficients for historical and social 
aspirations as predictors. This allowed us to test whether effect sizes vary under differential influence of historical and social aspirations on the joint aspiration level.

\section{RESULTS}

Insert Table 2 about here

Table 2 presents the meta-analytic correlation matrix, which contains the mean effect sizes and standard errors below the diagonal, while the number of firms and number of effect sizes is reported above the diagonal.

Table 3 reports the bare-bones meta-analyses and heterogeneity statistics for our four main meta-analyses. Responsiveness to $\mathrm{P}<\mathrm{HA}$ is heterogeneous, as the Q-statistic is 353.47 ( $p$ value $<0.001, I^{2}=83.59$, and $\tau^{2}=0.00782$ ). Responsiveness to $\mathrm{P}>\mathrm{HA}$ is heterogeneous, as the Q-statistic is 217.5 ( $p$-value $<0.001, I^{2}=74.25$, and $\tau^{2}=0.00449$ ). Responsiveness to $\mathrm{P}<\mathrm{SA}$ is heterogeneous, as the Q-statistic is 343.78 ( $p$-value $<0.001, I^{2}=79.64$, and $\tau^{2}=0.00564$ ). Responsiveness to $\mathrm{P}>\mathrm{SA}$ is heterogeneous, as the $\mathrm{Q}$-statistic is 313.89 ( $p$-value $<0.001, I^{2}=$ 78.02, and $\tau^{2}=0.00522$ ). These findings suggest that the core prediction of PFT needs to be revisited and elaborated, as evidently not all types of performance feedback are related in the same way to organizational responsiveness.

Insert Table 3 about here

In Research Question 1 we asked whether performance feedback valence affects the strength of the relationship between performance feedback and organizational responsiveness. We found that the explained variance for the full model with respect to negative performance feedback is $2.63 \%$ and $2.01 \%$ for positive performance feedback, indicating that the explanatory power of performance feedback relating to organizational responsiveness is larger for negative performance feedback. We also tested whether the coefficients for negative and positive performance feedback are different through a MASEM using all types of responsiveness (Table 
4). We found a significant negative coefficient for performance below historical aspiration levels $\left(\beta=-0.04, C I_{95}=[-0.05,-0.02]\right)$ and a non-significant negative coefficient for performance above historical aspiration levels $\left(\beta=-0.00, C I_{95}=[-0.02,-0.01]\right)$. The difference between these coefficients is significant $(p$-value $=0.003$ ). We found a non-significant negative coefficient for performance below social aspiration levels $\left(\beta=-0.01, C I_{95}=[-0.03,0.01]\right)$ and a non-significant negative coefficient for performance below social aspiration levels $\left(\beta=-0.01, C I_{95}=[-0.02\right.$, 0.01]). The differences between these coefficients are not significant ( $p$-value $=0.837$ ). Together, these findings suggest that negative performance feedback not only better explains, but also induces more, organizational responsiveness than positive performance feedback.

To test Hypothesis 1, we compared the effects of historical and social performance feedback on organizational responsiveness. The results of our MASEMs show a nuanced picture. First, findings displayed in Table 4 show that both the sign and size of the effect of historical and social performance feedback on organizational responsiveness differ between negative and positive performance feedback. Organizations are significantly more responsive to performance below historical aspiration levels as compared to performance below social aspiration levels ( $\beta=$ $0.03, p$-value $=0.039)$. With respect to performance above an aspiration level, we find that organizational responsiveness doesn't differ between historical and social performance feedback $(\beta=0.00, p$-value $=0.711)$. These findings suggest that historical performance feedback elicits higher responsiveness than social performance feedback does, although the difference in effect sizes is rather small. Overall, these findings partially support hypothesis 1. Insert Table 4 about here

Hypothesis 2 aimed to look at another dimension of performance feedback - nonfinancial versus financial performance feedback - and whether this invokes distinct levels of 
responsiveness. Our findings (Table 5) related to the type of performance indicator suggest differential effects. The level of organizational responsiveness to performance below historical levels is similar for both financial- and non-financial performance feedback $(\beta=-0.01, p$-value $=$ 0.268). However, for performance above historical aspiration levels we find that organizations are less responsive to non-financial performance feedback ( $\beta=-0.07, p$-value $<0.001)$. Moreover, we also find that organizations are less responsive to non-financial performance feedback for performance below social aspiration levels as compared to financial performance feedback $(\beta=0.08, p$-value $=0.011)$. For performance above social aspiration levels we find that organizations are more responsive to non-financial performance feedback, though the degree of support we find is marginal $(\beta=0.07, p$-value $=0.083)$. Overall, these findings suggest that organizations are more responsive to financial performance feedback when performing better than before and when performing below the average of their peers, but are more responsive to non-financial performance feedback when performing above social aspiration levels. Insert Table 5 about here

Research Question 2 addressed to what extent the effect of performance feedback on organizational responsiveness differs for search and change. The results of separate MASEMs for search and change are found in Table 4 above. First, we find that the amount of explained variance in the model for all types of organizational responsiveness is $2.71 \%$, while the explained variance increases to $4.46 \%$ for the search model, and to $4.25 \%$ for the change model. Second, we find that negative performance feedback induces search significantly more than change (P < HA: $p$-value $<0.001$; P $>$ HA: $p$-value $<0.001$ ). At the same time, we find no significant differences between the search and change model for social performance feedback. Overall, these results support the notion that specifying the type of organizational responsiveness 
improves the explanatory power of performance feedback models while they also show that historical performance feedback induces search more than change.

Hypothesis 3 stated that organizational responsiveness to performance feedback decreases with organizational age. If firm age in Table 5 reports a positive coefficient for performance below aspiration levels $(\mathrm{P}<\mathrm{HA} \& \mathrm{P}<\mathrm{SA})$, then increasing firm age is associated with decreasing organizational responsiveness. We find partial support for hypothesis 3 , as performance below historical and social aspiration levels have significant positive effects, which means that older organizations are less responsive to negative performance feedback ( $\mathrm{P}<\mathrm{HA}$ : $\beta$ $=0.001, p$-value $<0.001 ; \mathrm{P}<\mathrm{SA}: \beta=0.001, p$-value $=0.001)$. However, no statistically significant effects were found for the effect of organizational age on the association of positive performance feedback and responsiveness $(\mathrm{P}>\mathrm{HA}: \beta=0.00, p$-value $=0.464 ; \mathrm{P}>\mathrm{SA}: \beta=0.00$, $p$-value $=0.505)$. Thus, firms indeed become less responsive to negative performance feedback as they grow older, whereas age has no impact on the influence of positive performance feedback on organizational responsiveness.

Our results, as reported in Table 5, provide partial support for Hypothesis 4. We proposed that public firms are more responsive to performance feedback than privately owned firms. We find that private firms are significantly less responsive to performance below both historical and social aspiration levels $(\mathrm{P}<\mathrm{HA}: \beta=0.13, p$-value $=<0.001 ; \mathrm{P}<\mathrm{SA}: \beta=0.17, p$-value $<$ 0.001). However, private firms are significantly more responsive to performance above both historical and social aspiration levels $(\mathrm{P}>\mathrm{HA}: \beta=0.06, p$-value $=0.045 ; \mathrm{P}>\mathrm{SA}: \beta=0.11, p$ value $=0.006$ ). A potential explanation is that publicly owned firms are pressurized by their shareholders to act when they perform below aspiration levels, while shareholders engage in rent-extraction when firms perform above aspiration levels. 
Hypothesis 5 stated that organizations are more responsive to social than to historical performance feedback in high tech industries. The arithmetic mean of the sample size $(N=383)$ for this model is a lot lower than in the previous models, as the number of studies in high-tech environments is rather small $(K=39)$. Therefore, we also estimated this MASEM using the amount of observations as a sensitivity analysis $(N=2821)$ with increased statistical power. We tested Hypothesis 5 using the number of observations as sample size and report all results in Table 6. We find evidence for hypothesis 5, as organizations are significantly more responsive to performance below social aspiration levels $(\beta=0.07, p$-value $=0.045)$. Organizations are also more responsive to performance above social aspiration levels $(\beta=0.13, p$-value $=0.003)$. The effects for both models have a similar sign and size. These findings imply that historical performance feedback seems to be less relevant, whereas social performance feedback is particularly instrumental in uncertainty avoidance in high tech industries.

Insert Table 6 about here

\section{Robustness Checks}

We ran several robustness checks to assess the stability of our results. The complete results of all robustness checks can be found in the appendix, due to space limitations ${ }^{9}$. First, separate meta-regressions were run on several methodological moderators. We find that the effect of performance above historical aspiration levels on organizational responsiveness is significantly larger for studies with 1-year lagged aspiration levels as compared to longer-term lagged aspiration levels. We find that published studies show larger effects than unpublished studies for performance above historical aspiration levels, which is a sign of publication bias. We also find that continuously measured types of organizational responsiveness have smaller effects than dichotomously measured responsiveness for performance below historical aspiration levels. 
Last, we also find that the effect of performance above social aspiration levels is significantly larger for studies that use the industry average as reference group when compared to studies that use more specific reference groups. All other methodological moderators appear to have no significant influence on effect sizes in our models.

Second, we ran HiLMMA on all primary analyses (Marano et al., 2016; Raudenbush \& Bryk, 2002). The sign and size of effect sizes for the search model is similar. For the organizational change model, the sign and size of effect sizes is the same but now also significant. These results indicate the absence of stochastic dependencies. For the metaregressions, form of ownership is no longer significantly related to performance above the historical aspiration level. The effects are robust to stochastic dependencies for the remaining predictors of interest, indicating the relative stability of the results to various specifications. Last, we fail to find support for hypothesis 7 using HiLMMA (P $<\mathrm{A}$ : $\beta=-0.003, p$-value $=0.982 ; \mathrm{P}>$ A: $\beta=0.10, p$-value $=0.394)$ which warrants cautious interpretation of the main results.

Third, we ran MASEMs for search and change using the Cyert and March (1963) specification. The effect sizes for both models are small and insignificant, which adds to the evidence that historical and social aspiration levels should be estimated separately in performance feedback research (Bromiley \& Harris, 2014). Interestingly, the weights that influence the estimation of the single aspiration level appear to have no influence on the magnitude of the relationship between performance feedback and organizational responsiveness. This provides further evidence for using the 'separate model' in aspiration estimation.

\section{DISCUSSION \& CONCLUSION}

In this paper we explore the tenability of the core explanatory mechanism in PFT, which as we discussed earlier concerns how satisficing drives organizational responsiveness. We do so because, despite contestation regarding key elements of the theory and accumulation of 
heterogeneous empirical evidence (Klingebiel, 2017; Posen et al., 2018; Shinkle, 2012), the core prediction introduced by Cyert and March (1963) derived from satisficing has continued to dominate the field (Posen et al., 2018). Following this core prediction, studies focusing on PFT predict organizations will be more responsive to negative performance feedback than positive performance feedback, irrespective of the type of aspiration level, performance indicator, type of responsiveness and organizational characteristics. While this issue has been addressed in literature reviews and conceptual contributions (Klingebiel, 2017; Posen et al., 2018; Shinkle, 2012), the inferential statistics-based synthesis of the available empirical evidence we achieve with our meta-analysis offers a much needed and novel contribution to revisit and elaborate PFT. Overall, our results demonstrate that organizations respond to performance feedback, which confirms that performance feedback can explain organizational responsiveness (Greve, 2003b). Although our findings are generally complementary to received wisdom, they offer considerable new insights that open up new avenues for research and offer fruitful extensions to the theory.

Our most basic analysis, with which we examined Research Question 1 regarding the valence of performance feedback, provided a confirmation of the heterogeneity in findings signaled in the narrative reviews (Klingebiel, 2017; Posen et al., 2018; Shinkle, 2012) and moreover allowed us to assess the nature of this heterogeneity. In line with the core prediction of PFT, in the aggregate negative performance feedback is associated with increased responsiveness. This finding indicates that organizations feel the urgency to act when performing below aspiration levels (Desai, 2016; Greve, 2003a). However, deviating from the core prediction of PFT, organizations do not systematically decrease responsiveness when facing positive performance feedback. Our findings indicate substantial heterogeneity in the relationship between positive performance feedback and organizational responsiveness, which 
implies that organization consider a wide(r) variety of responses, ranging from complacency to slack search (Baum et al., 2005). Given this finding, future research on PFT can no longer assume that organizational responsiveness declines when performance exceeds aspiration levels, as predicted based on the satisficing mechanism. Instead, scholars can advance PFT by identifying factors that explain when, under conditions of positive performance feedback, an organization becomes complacent or engages in experimentation.

In further analyses, we examined how the relationship between performance feedback and organizational responsiveness would be sensitive to variation in specific dimensions of performance feedback, types of responsiveness, and organizational characteristics. First, with respect to how performance feedback based on distinct types of aspiration levels affects organizational responsiveness, we discuss the findings on Hypotheses 1 and 5 because they both address the differential effect of historical versus social performance feedback. We found that organizations were more responsive to historical performance feedback relative to social performance feedback, supporting Hypothesis 1. In line with earlier research (Greve, 2003a; Kim et al., 2015), this finding suggests organizations overvalue their own uniqueness rendering social performance feedback less relevant. Organizations have difficulty determining a relevant peer group to facilitate proper use of social performance feedback given the many criteria by which this can be done, or a combination of these factors (Baum et al., 2005; Greve, 2003b). However, in a subsample of firms active in high tech industries, we found the reverse pattern, supporting Hypothesis 5. These results reveal a stronger influence of social performance feedback than historical performance feedback on organizational responsiveness in high tech industries. In such industries, as some scholars have proposed (Greve, 2003b), historical performance seemingly loses its diagnostic value because performance is more volatile, inducing higher uncertainty. 
Comparing against competitors and striving to outcompete them becomes more relevant, as these peers are subject to the same dynamics, rendering social performance feedback more valuable to avoid uncertainty, relative to historical performance feedback. In sum we conclude that, given the combined findings pertaining to Hypotheses 1 and 5, future research efforts are needed to identify where, when, and why historical performance feedback instigates higher levels of responsiveness as compared to the social performance feedback. This could start with more precise measure of environmental turbulence than the coarse proxy we employed here. Moreover, various operative mechanisms, such as self-enhancement (Audia \& Brion, 2007), sequential attention (Greve, 2008), or holistic consideration (Lucas et al., 2018), should be investigated as the extent of volatility in the organizational environment may alter the prevalence of which operative mechanism is at play to assess performance.

Second, our findings with respect to Hypothesis 2 indicate the relevance of a specific type of performance indicator, i.e., financial versus non-financial performance feedback, varies depending on both performance feedback valence and the type of aspiration level. Organizations were more responsive to financial performance feedback following performance above historical aspiration levels and performance below social aspiration levels, while they would respond more strongly when experiencing performance above social aspiration levels. These results indicate a more nuanced picture than we hypothesized. Our prediction was that non-financial performance feedback would generate greater levels of organizational responsiveness by virtue of the feedback being more specific and thereby informative for deciding if and how to act (Venkatraman \& Ramanujam, 1986). Conversely, financial performance feedback would serve as a master switch, in Greve's (2003a) terminology, resulting in higher (lower) responsiveness of any type given negative (positive) performance feedback. Again, these results indicate how 
differentiating along a relevant dimension of performance feedback helps to uncover different patterns in the performance feedback-responsiveness relationship. Notably, these results also suggest that performance below historical aspiration levels, no matter the performance indicator in which this occurs, represent a problem organizations need to deal with as a matter of urgency (Baum et al., 2005; Greve, 1998; Lucas et al., 2018). Furthermore, these conclusions underscore the need to explain where and by which mechanism these shifts in the importance and influence of distinct dimensions of performance feedback occur.

Third, our findings with respect to Research Question 2 show that the type of organizational responsiveness, search or change, matters. The results indicate that the explained variance of the relationship between search and performance feedback is only a fraction larger than the relationship between change and performance feedback. However, regarding the magnitude of the relationship, our MASEM results indicate that the effect of historical performance feedback on search is greater than the effect on change. This suggests that PFT is a theory better suited for predicting the search for potential solutions rather than the actual implementation of potential solutions, which seems to be in line with the original process model of Cyert and March (1963) in which search precedes change. However, there are no PFT papers to our knowledge that test if search and change indeed follow such a sequential structure as Posen et al. (2018) propose should be the approach to examine PFT. Therefore, sequential analyses or full-fledged process study approaches are called for.

Shifting focus, our results showed that certain organizational characteristics are important boundary conditions to the influence of performance feedback on organizational responsiveness. In line with Hypothesis 3, we found that organizational responsiveness to performance feedback decreases when organizations grow older though only for negative but not positive performance 
feedback. Furthermore, organizational age and search are negatively associated $(\beta=-0.059$, Table 2) while organizational age and change are positively related $(\beta=0.030$, Table 2$)$. These results suggest that organizations assemble a set of strategies and solutions through search. Over time, the degree of search is reduced in favor of relying on implementing solutions derived from prior search.

Our results for Hypothesis 4 paint a more nuanced picture than we predicted. Publicly owned organizations were more responsive to negative performance feedback in agreement with our prediction, while they were less responsive to positive performance feedback contrary to what we hypothesized. When listed firms perform below aspiration levels, shareholders may pressure the organization to change their current set of activities because they are seen as ineffective (Mitroff, 1983; Dutton and Duncan, 1987). Failure to satisfy shareholder goals and expectations has also been shown to impair managerial power through increased monitoring of the board, replacement of managers and even hostile takeovers (Davis \& Stout, 1992; Tuggle, Sirmon, Reutzel, \& Bierman, 2010; Wiersema \& Zhang, 2011). When such organizations perform above aspirations, shareholders are likely to engage in rent extraction, thus limiting the amount of resources for experimentation (slack search). Moreover, the current repertoire is seen as effective, which limits managerial discretion to search for more alternative solutions.

Next to suggestions for theoretical extensions of PFT, we are able to provide a number of suggestion on designing future research. First, when designing a PFT study the choice of performance indicator(s), type of aspiration level, type of organizational responsiveness, and boundary conditions to be included merit careful consideration. Our findings demonstrated that these matter for the strength and direction of the relationship between performance feedback and organizational responsiveness. Second, we strongly recommend the use of experiments as a tool 
to causally disentangle which dimensions of performance feedback lead to which types of responsiveness (see e.g. Audia \& Brion, 2007). Experiments are especially suitable for examining underlying mechanisms, such as those explaining shifts in the importance and influence of distinct dimensions of performance feedback as referred to above. As the dominant research design in PFT continues to be archival data analysis, which is less suitable for addressing the questions for future research we identified, questionnaires (e.g., Tarakci, Ateş, Floyd, Ahn, \& Wooldridge, 2018) and qualitative research designs should be implemented as well. Third, we found no studies that explicitly tested the link between non-financial performance feedback and search. Thus, assessing whether performance of a more specific nature relative to an aspiration level leads to faster and more comprehensive search processes would be a fruitful avenue for further study.

The findings on organizational characteristics indicate two clear avenues for future study. First, our results on age and form of ownership taken together point to a need to consider managerial discretion in further refining PFT. As organizational routines and operating procedures solidify over time, managerial discretion is reduced. Moreover, while publicly listed firms are more responsive to negative performance feedback, the "earnings obsession" (Graham, Harvey, \& Rajgopal, 2005) of financial markets actually constrains managerial discretion, which diverts managerial focus to short-term solutions. Further research is necessary to explore how managerial discretion influences organizational responsiveness to performance feedback. In particular, it should determine whether and to what extent managerial discretion constrains or enables responsiveness to historical and/or social performance feedback.

Second, our results offer an opportunity to theorize and examine the influence of dominant coalition dynamics on how organizations respond to performance feedback (Argote \& 
Greve, 2007). Cyert and March (1963) noted that while aspirations drive organizational change, dominant coalitions matter for which alternative solution is chosen. Recent work demonstrated that the constellation of the board of directors and political dynamics predict specific directions of organizational change (Desai, 2016; Zhang \& Greve, 2018). Since dominant coalitions change and evolve as organizations age, especially where it concerns large publicly owned firms, more research is needed to assess how organizational characteristics in conjunction with characteristics of the dominant coalition drive the extent and direction of organizational change.

Our meta-analysis has several limitations. First, the dependent variables of studies in our meta-analyses vary, as we included dichotomous, count, and continuous measures of search and change. Some primary studies with dichotomous and count variables report Pearson correlations, which tend to be smaller in size than the Spearman or point-biserial correlations that ought to be reported. This might have reduced the power of our meta-analyses. We tried to mitigate this issue by estimating whether effect sizes between performance feedback and responsiveness were smaller for dependent variables that were measured as continuous variables. While we only found a small difference for performance above historical aspiration levels, we nevertheless warrant caution with the interpretation of our results.

Second, some of the aforementioned findings are based on a relatively small set of studies which limits a broad generalization. We took several steps to check the robustness of our results, such as outlier analyses for the main effects and multilevel meta-analysis. The results of the MASEMs are stable for all the specified models, but the MARA results are somewhat dependent on the type of analyses. Future research on the contingencies tested here might advance our understanding of boundary conditions that pertain to organizational responsiveness 
following performance feedback, as well as conditions under which organizations do not respond

to performance feedback. Doing so contributes to a more comprehensive account of PFT.

\section{REFERENCES}

Argote, L., \& Greve, H. R. 2007. A behavioral theory of the firm - 40 years and counting: Introduction and impact. Organization Science, 18(3): 337-349.

Audia, P. G., \& Brion, S. 2007. Reluctant to change: Self-enhancing responses to diverging performance measures. Organizational Behavior and Human Decision Processes, 102(2): $255-269$.

Audia, P. G., \& Greve, H. R. 2006. Less likely to fail: Low performance, firm size, and factory expansion in the shipbuilding industry. Management Science, 52(1): 83-94.

Audia, P. G., Locke, E. A., \& Smith, K. G. 2000. The Paradox of Success: An Archival and a Laboratory Study of Strategic Persistence Following Radical Environmental Change. Academy of Management Journal, 43(5): 837-853.

Barney, J. 1991. Firm Resources and Sustained Competitive Advantage. Journal of Management, 17(1): 99-120.

Baum, J. A. C., Rowley, T. J., Shipilov, A. V., \& Chuang, Y.-t. 2005. Dancing with strangers: Aspiration performance and the search for underwriting syndicate partners. Administrative Science Quarterly, 50(4): 536-575.

Bergh, D. D., Aguinis, H., Heavey, C., Ketchen, D. J., Boyd, B. K., Su, P., Lau, C. L. L., \& Joo, H. 2016. Using meta-analytic structural equation modeling to advance strategic management research: Guidelines and an empirical illustration via the strategic leadership-performance relationship. Strategic Management Journal, 37(3): 477-497.

Bijmolt, T. H., \& Pieters, R. G. 2001. Meta-analysis in marketing when studies contain multiple measurements. Marketing Letters, 12(2): 157-169.

Blettner, D. P., He, Z.-L., Hu, S., \& Bettis, R. A. 2015. Adaptive aspirations and performance heterogeneity: Attention allocation among multiple reference points. Strategic Management Journal, 36(7): 987-1005.

Bromiley, P. 1991. Testing a causal model of corporate risk taking and performance. Academy of Management Journal, 34(1): 37-59.

Bromiley, P., \& Harris, J. D. 2014. A comparison of alternative measures of organizational aspirations. Strategic Management Journal, 35(3): 338-357.

Buyl, T., \& Boone, C. 2014. Exploration versus exploitation: The differential impact of historical and social comparison performance feedback on executives' cognitive orientation. In Behavioral strategy: Emerging perspectives (pp. 27-54).

Capron, L., \& Shen, J.-C. 2007. Acquisitions of private vs. public firms: Private information, target selection, and acquirer returns. Strategic Management Journal, 28(9): 891-911. 
Chatterjee, A., \& Hambrick, D. C. 2007. It's All about Me: Narcissistic Chief Executive Officers and Their Effects on Company Strategy and Performance. Administrative Science Quarterly, 52(3): 351-386.

Chatterjee, A., \& Hambrick, D. C. 2011. Executive Personality, Capability Cues, and Risk Taking. Administrative Science Quarterly, 56(2): 202-237.

Chen, W.-R. 2008. Determinants of firms' backward- and forward-looking R\&D search behavior. Organization Science, 19(4): 609-622.

Chen, W.-R., \& Miller, K. D. 2007. Situational and institutional determinants of firms' R\&D search intensity. Strategic Management Journal, 28(4): 369-381.

Combs, J. G., Ketchen Jr, D. J., Crook, T. R., \& Roth, P. L. 2011. Assessing Cumulative Evidence within 'Macro' Research: Why Meta-Analysis Should be Preferred Over Vote Counting. Journal of Management Studies, 48(1): 178-197.

Cyert, R. M., \& March, J. G. 1963. A behavioral theory of the firm. Englewood Cliffs, NJ: Prentice-Hall.

Davis, G. F., \& Stout, S. K. 1992. Organization Theory and the Market for Corporate Control: A Dynamic Analysis of the Characteristics of Large Takeover Targets, 1980-1990. Administrative Science Quarterly, 37(4): 605.

Deephouse, D. L., \& Wiseman, R. M. 2000. Comparing alternative explanations for accounting risk-return relations. Journal of Economic Behavior \& Organization, 42(4): 463-482.

Desai, V. M. 2008. Constrained growth: How experience, legitimacy, and age influence risk taking in organizations. Organization Science, 19(4): 594-608.

Desai, V. M. 2016. The Behavioral Theory of the (Governed) Firm: Corporate Board Influences on Organizations Responses to Performance Shortfalls. Academy of Management Journal, 59(3): 860-879.

Donaldson, L. 1987. Strategy and structural adjustment to regain fit and performance: in defence of contingency theory. Journal of Management Studies, 24(1): 1-24.

Drees, J. M., \& Heugens, P. P. M. A. R. 2013. Synthesizing and extending resource dependence theory: A meta-analysis. Journal of Management, 39(6): 1666-1698.

Eisenhardt, K. M., \& Martin, J. A. 2000. Dynamic capabilities: what are they? Strategic Management Journal, 21(10-11): 1105-1121.

Fitza, M., \& Tihanyi, L. 2017. How Much Does Ownership Form Matter? Strategic Management Journal, 38(13): 2726-2743.

Gavetti, G., Greve, H. R., Levinthal, D. A., \& Ocasio, W. 2012. The behavioral theory of the firm: Assessment and prospects. The Academy of Management Annals, 6(1): 1-40. 
Geyskens, I., Krishnan, R., Steenkamp, J.-B. E. M., \& Cunha, P. V. 2009. A review and evaluation of meta-analysis practices in management research. Journal of Management, 35(2): 393-419.

Gong, Y., Zhang, Y., \& Xia, J. 2017. Do firms learn more from small or big successes and failures? A test of the outcome-based feedback learning perspective. Journal of Management.

Gonzalez-Mulé, E., \& Aguinis, H. 2017. Advancing theory by assessing boundary conditions with metaregression: A critical review and best-practice recommendations. Journal of Management.

Graham, J. R., Harvey, C. R., \& Rajgopal, S. 2005. The economic implications of corporate financial reporting. Journal of Accounting and Economics, 40(1-3): 3-73.

Greene, W. H. 1993. Econometric analysis. New York: Macmillan.

Greve, H. R. 1998. Performance, aspirations, and risky organizational change. Administrative Science Quarterly, 43(1): 58-86.

Greve, H. R. 2003a. A behavioral theory of R\&D expenditures and innovations: Evidence from shipbuilding. Academy of Management Journal, 46(6): 685-702.

Greve, H. R. 2003b. Organizational learning from performance feedback: A behavioral perspective on innovation and change. Cambridge University Press.

Greve, H. R. 2008. A behavioral theory of firm growth: Sequential attention to size and performance goals. Academy of Management Journal, 51(3): 476-494.

Greve, H. R. 2010. Designing Performance Feedback Systems to Guide Learning and Manage Risk. Organizational Dynamics, 39(2): 104-114.

Hedges, L. V., \& Olkin, I. 1985. Statistical models for meta-analysis. New York: Academic Press.

Hedges, L. V., \& Olkin, I. 2014. Statistical methods for meta-analysis. New York: Academic Press.

Higgins, J. P. T., \& Thompson, S. G. 2002. Quantifying heterogeneity in a meta-analysis. Statistics in Medicine, 21(11): 1539-1558.

Jak, S. 2015. Methods for meta-analytic structural equation modeling. In Meta-analytic structural equation modelling (pp. 15-23).

Joseph, J. 2014. Attention in Complex Organizations: Top-down and Bottom-up Attention and Transition to New Technologies.

Joseph, J., \& Gaba, V. 2015. The fog of feedback: Ambiguity and firm responses to multiple aspiration levels. Strategic Management Journal, 36(13): 1960-1978. 
Keil, T., Kostopoulos, K., Syrigos, E., \& Meissner, F. 2016. Learning from performance feedback in complex environments. Retrieved from https://www.researchgate.net/publication/307639857\{_\}LEARNING\{\_\}FROM\{\_\}PE RFORMANCE\{ $\left.\_\right\} F E E D B A C K\{\backslash\} I N\{\backslash\} C O M P L E X\{\lfloor\} E N V I R O N M E N T S$

Ketchen, D. J., \& Palmer, T. B. 1999. Strategic Responses to Poor Organizational Performance: A Test of Competing Perspectives. Journal of Management, 25(5): 683-706.

Kim, J.-Y., Finkelstein, S., \& Haleblian, J. 2015. All aspirations are not created equal: The differential effects of historical and social aspirations on acquisition behavior. Academy of Management Journal, 58(5): 1361-1388.

Klingebiel, R. 2017. Risk-type preference shifts in response to performance feedback. Strategic Organization, 147612701770256.

Knapp, G., \& Hartung, J. 2003. Improved tests for a random effects meta-regression with a single covariate. Statistics in Medicine, 22(17): 2693-2710.

Lant, T. K. 1992. Aspiration level adaptation: An empirical exploration. Management Science, 38(5): 623-644.

Le Mens, G., Hannan, M. T., \& Pólos, L. 2015. Age-Related Structural Inertia: A DistanceBased Approach. Organization Science, 26(3): 756-773.

Lehman, D. W., Hahn, J., Ramanujam, R., \& Alge, B. J. 2011. The Dynamics of the Performance-Risk Relationship Within a Performance Period: The Moderating Role of Deadline Proximity. Organization Science, 22(6): 1613-1630.

Lipsey, M. W., \& Wilson, D. B. 2001. Practical meta-analysis. Thousand Oaks, CA: Sage.

Lucas, G. J. M., Knoben, J., \& Meeus, M. T. H. 2018. Contradictory yet Coherent? Inconsistency in Performance Feedback and R\&D Investment Change. Journal of Management, 44(2): 658-681.

Lungeanu, R., Stern, I., \& Zajac, E. J. 2016. When do firms change technology-sourcing vehicles? The role of poor innovative performance and financial slack. Strategic Management Journal, 37(5): 855-869.

Marano, V., Arregle, J.-L., Hitt, M. A., Spadafora, E., \& Essen, M. van. 2016. Home Country Institutions and the Internationalization-Performance Relationship. Journal of Management, 42(5): 1075-1110.

March, J. G., \& Simon, H. A. (1958). Organizations. New York: John Wiley \& Sons.

Parker, O. N., Krause, R., \& Covin, J. G. 2017. Ready, Set, Slow: How Aspiration-Relative Product Quality Impacts the Rate of New Product Introduction. Journal of Management, 43(7): 2333-2356.

Peteraf, M. A. 1993. The cornerstones of competitive advantage: A resource-based view. Strategic Management Journal, 14(3): 179-191. 
Posen, H. E., Keil, T., Kim, S., \& Meissner, F. D. 2018. Renewing Research on Problemistic Search-A Review and Research Agenda. Academy of Management Annals, 12(1): 208251.

R Core Team. 2017. R: A Language and Environment for Statistical Computing. Vienna, Austria: R Foundation for Statistical Computing. Retrieved from https://www.rproject.org/

Raudenbush, S. W., \& Bryk, A. S. 2002. Hierarchical linear models: Applications and data analysis methods (Vol. 1). Sage.

Ref, O., \& Shapira, Z. 2017. Entering new markets: The effect of performance feedback near aspiration and well below and above it. Strategic Management Journal, 38(7): 14161434.

Rosseel, Y. 2012. lavaan: An R package for structural equation modeling. Journal of Statistical Software, 48(2): 1-36.

Rudy, B. C., \& Johnson, A. F. 2016. Performance, aspirations, and market versus nonmarket investment. Journal of Management, 42(4): 936-959.

Samba, C., Knippenberg, D. V., \& Miller, C. C. 2017. The impact of strategic dissent on organizational outcomes: A meta-analytic integration. Strategic Management Journal, 124.

Schmidt, F. L., \& Hunter, J. E. 2014. Methods of meta-analysis: Correcting error and bias in research findings. Thousand Oaks, CA: Sage.

Sengul, M., \& Obloj, T. 2017. Better safe than sorry: Subsidiary performance feedback and internal governance in multiunit firm. Journal of Management, 43(8): 2526-2554.

Shimizu, K., \& Hitt, M. A. 2005. What constrains or facilitates divestitures of formerly acquired firms? The effects of organizational inertia. Journal of Management, 31(1): 50-72.

Shinkle, G. A. 2012. Organizational aspirations, reference points, and goals: Building on the past and aiming for the future. Journal of Management, 38(1): 415-455.

Shipilov, A. V., Li, S. X., \& Greve, H. R. 2011. The Prince and the Pauper: Search and Brokerage in the Initiation of Status-Heterophilous Ties. Organization Science, 22(6): 1418-1434.

Short, J. C., \& Palmer, T. B. 2003. Organizational performance referents: An empirical examination of their content and influences. Organizational Behavior and Human Decision Processes, 90(2): 209-224.

Simon, H. A. (1957). Models of man; social and rational. New York: John Wiley \& Sons.

Singh, J. V. 1986. Performance, slack, and risk taking in organizational decision making. Academy of Management Journal, 29(3): 562-585. 
Staw, B. M., Sandelands, L. E., \& Dutton, J. E. 1981. Threat rigidity effects in organizational behavior: A multilevel analysis. Administrative Science Quarterly, 26(4): 501.

Tarakci, M., Ateş, N. Y., Floyd, S. W., Ahn, Y., \& Wooldridge, B. 2018. Performance feedback and middle managers' divergent strategic behavior: The roles of social comparisons and organizational identification. Strategic Management Journal, 39(4): 1139-1162.

Teece, D. J. 2007. Explicating dynamic capabilities: the nature and microfoundations of (sustainable) enterprise performance. Strategic Management Journal, 28(13): 1319-1350.

Thornhill, S., \& Amit, R. 2003. Learning About Failure: Bankruptcy, Firm Age, and the Resource-Based View. Organization Science, 14(5): 497-509.

Tuggle, C. S., Sirmon, D. G., Reutzel, C. R., \& Bierman, L. 2010. Commanding board of director attention: Investigating how organizational performance and CEO duality affect board members' attention to monitoring. Strategic Management Journal, 31(9): 946-968.

Tyler, B. B., \& Caner, T. 2016. New product introductions below aspirations, slack and R\&D alliances: A behavioral perspective. Strategic Management Journal, 37(5): 896-910.

Venkatraman, N., \& Ramanujam, V. 1986. Measurement of Business Performance in Strategy Research: A Comparison of Approaches. Academy of Management Review, 11(4): 801814.

Viechtbauer, W. 2005. Bias and efficiency of meta-analytic variance estimators in the randomeffects model. Journal of Educational and Behavioral Statistics, 30(3): 261-293.

Viechtbauer, W. 2010. Conducting meta-analyses in R with the metafor package. Journal of Statistical Software, 36(3): 1-48.

Viechtbauer, W., López-López, J. A., Sánchez-Meca, J., \& Marín-Martínez, F. 2015. A comparison of procedures to test for moderators in mixed-effects meta-regression models. Psychological Methods, 20(3): 360-374.

Villagrasa, J., Buyl, T., \& Escribá-Esteve, A. 2017. CEO satisfaction and intended strategic changes: The moderating role of performance cues. Long Range Planning.

Wiersema, M. F., \& Zhang, Y. 2011. CEO Dismissal: The role of investment analysts. Strategic Management Journal, 32(11): 1161-1182.

Zhang, C. M., \& Greve, H. R. 2019. Dominant coalitions directing acquisitions: Different decision makers, different decisions. Academy of Management Journal, 62(1): 44-65. 


\section{FOOTNOTES}

1. The average number of publications per year for studies focusing on PFT was 2.8 in the period 2000-2009 and increased to 13.4 in the period 2010-2017.

2. Far less frequently, PFT scholars have examined a third component from the original Cyert \& March (1963) model: aspiration updating. Unfortunately, the number of studies on this topic was too low for purposes of a meta-analysis and we were unable to include it.

3. Link to supplementary material:

https://osf.io/af2px/?view_only=94f2faad76094b128b51118583f3020f

4. Greve (2003a, 2003b) theorized that shifts in managerial willingness to take risk is a main factor in explaining the greater level of organizational search and change when confronted with negative performance feedback. Thus, while risk is important in explaining organizational responsiveness to performance feedback, it is an aspect of search and change rather than a separate type of organizational responsiveness.

5. We searched the Journal of Management, Academy of Management Journal, Administrative Science Quarterly, Group \& Organization Management, Industrial and Corporate Change, Journal of Business Research, Journal of Economic Behavior and Organization, Journal of Management Studies, Management Science, Organization Science, Organizational Behavior and Human Decision Processes, Research Policy, Strategic Management Journal, and Strategic Organization.

6. Link to supplementary material:

7. Previous literature indicates the direct and moderating influence of organizational age. We included organizational age in the MASEMs to control for its direct influence on organizational responsiveness. We used organizational age as a moderating variable in the MARAs to test Hypothesis 3.

8. We used the ML estimator instead of the DerSimonian-Laird (DL) estimator (Viechtbauer, 2005), as metafor does not allow the DL estimator for HiLMMA.

9. Link to supplementary material:

https://osf.io/af2px/?view_only=94f2faad76094b128b51118583f3020f 


\section{TABLES}

Table 1

\section{Constructs and Definitions Table}

\begin{tabular}{|c|c|}
\hline Construct & Definition \\
\hline Aspiration level & $\begin{array}{l}\text { "Aspirations are desired performance levels in specific organizational outcomes" (Shinkle, 2012, p. 416). "... is the level of } \\
\text { future performance deemed acceptable" (Posen et al., 2018, p 218). }\end{array}$ \\
\hline Historical aspiration level & $\begin{array}{l}\text { An aspiration level that is "based on the focal organization's past performance" (Greve, 2003b, p. 9) or "a mixture of past- } \\
\text { period historical aspiration level and the previous performance (Greve, 2003a, p. 691). }\end{array}$ \\
\hline Social aspiration level & An aspiration level that is "based on the performance of other organizations" (Greve, 2003b, p. 9). \\
\hline Financial performance & $\begin{array}{l}\text { "Outcome-based financial indicators that are assumed to reflect the fulfilment of the economic goals of the firm (Venkatraman } \\
\text { \& Ramanujam, 1986, p. 803), such as return on assets (Greve, 2003b), revenue growth (Audia \& Brion, 2007), or sales (Ben-Oz } \\
\text { \& Greve, 2015). These measures of performance can be expressed in monetary units. }\end{array}$ \\
\hline Non-financial performance & $\begin{array}{l}\text { "Indicators of operational performance (i.e., non-financial) (Venkatraman \& Ramanujam, 1986, p. 804), such as product quality } \\
\text { (Parker et al., 2017), reputation (Baum et al., 2005), or the number of new product introductions (Tyler \& Caner, 2015). These } \\
\text { measures of performance are not expressed in monetary units. }\end{array}$ \\
\hline Organizational responsiveness & $\begin{array}{l}\text { The intensity at which certain organizational actions are executed or engaging in new actions, and thereby committing to certain } \\
\text { courses of action (Klingebiel, 2017). }\end{array}$ \\
\hline Search & $\begin{array}{l}\text { The generation of solutions that potentially correct or adapt the current set of organizational activities (Cyert \& March, 1963; } \\
\text { Greve, 2003b), such as investing in R\&D (Rudy \& Johnson, 2016). }\end{array}$ \\
\hline Change & $\begin{array}{l}\text { The implementation of one or more solutions that potentially correct or adapt the current set of organizational activities (Cyert } \\
\text { \& March, 1963; Greve, 2003b), such as entering a new market or changing products and services (Ketchen \& Palmer, 1999; } \\
\text { Parker et al., 2017). }\end{array}$ \\
\hline Performance feedback & "Performance relative to aspiration levels" (Greve 1998, p.59; Joseph \& Gaba, 2015). \\
\hline Performance feedback valence & $\begin{array}{l}\text { Whether performance is below an aspiration level (i.e., negative performance feedback) or whether performance is above an } \\
\text { aspiration level (i.e., positive performance feedback) (Gong et al., 2017). }\end{array}$ \\
\hline Negative performance feedback & A situation where performance is below an aspiration level (Greve 2003a; Klingebiel, 2017; Sengul \& Obloj, 2017). \\
\hline Positive performance feedback & A situation where performance is equal to or above an aspiration level (Tarakci et al., 2018; Xu et al., 2018). \\
\hline Historical performance feedback & A situation where performance is compared against a historical aspiration level (Baum et al., 2005; Joseph \& Gaba, 2015). \\
\hline Social performance feedback & A situation where performance is compared against a social aspiration level (Baum et al., 2005; Joseph \& Gaba, 2015). \\
\hline Financial performance feedback & A situation where financial performance is compared against a corresponding aspiration level (Greve, 2003b). \\
\hline Non-financial performance feedback & al performance is compared against a corresponding aspiration level (Parker et al., 2017). \\
\hline
\end{tabular}


Table 2

Meta-Analytic Correlation Matrix for all Types of Responsiveness

\begin{tabular}{|c|c|c|c|c|c|c|c|c|c|c|c|}
\hline & 1 & 2 & 3 & 4 & 5 & 6 & 7 & 8 & 9 & 10 & 11 \\
\hline 1. Organizational & & 43973 & 42320 & 54738 & 53198 & 26401 & 29248 & 12506 & 28690 & 49472 & 31453 \\
\hline Responsiveness & & 59 & 57 & 71 & 70 & 18 & 26 & 17 & 16 & 55 & 28 \\
\hline \multirow[t]{2}{*}{ 2. $\mathrm{P}<\mathrm{HA}$} & -0.03 & & 39039 & 32681 & 31141 & 25494 & 31426 & 14320 & 26808 & 37920 & 26687 \\
\hline & 0.02 & & 46 & 36 & 35 & 16 & 29 & 16 & 11 & 46 & 25 \\
\hline \multirow[t]{2}{*}{ 3. $\mathrm{P}>\mathrm{HA}$} & -0.02 & 0.13 & & 31141 & 31141 & 25381 & 31313 & 14207 & 26808 & 36267 & 25147 \\
\hline & 0.01 & 0.02 & & 35 & 35 & 15 & 28 & 15 & 11 & 44 & 24 \\
\hline \multirow[t]{2}{*}{ 4. $\mathrm{P}<\mathrm{SA}$} & -0.01 & 0.44 & 0.08 & & 49133 & 26476 & 27625 & 10231 & 26425 & 48019 & 29868 \\
\hline & 0.01 & 0.07 & 0.04 & & 51 & 17 & 25 & 13 & 10 & 48 & 25 \\
\hline \multirow[t]{2}{*}{ 5. $\mathrm{P}>\mathrm{SA}$} & 0.00 & 0.09 & 0.41 & 0.20 & & 26476 & 27625 & 10231 & 26425 & 46479 & 28328 \\
\hline & 0.01 & 0.04 & 0.05 & 0.03 & & 17 & 25 & 13 & 10 & 47 & 24 \\
\hline \multirow[t]{2}{*}{ 6. Absorbed slack } & -0.02 & -0.10 & 0.04 & -0.11 & 0.00 & & 24602 & 8372 & 22527 & 25751 & 18336 \\
\hline & 0.03 & 0.05 & 0.02 & 0.08 & 0.03 & & 15 & 9 & 6 & 18 & 9 \\
\hline \multirow[t]{2}{*}{ 7. Unabsorbed slack } & 0.01 & 0.04 & 0.02 & 0.06 & 0.06 & 0.11 & & 10168 & 23564 & 28644 & 19820 \\
\hline & 0.01 & 0.02 & 0.01 & 0.02 & 0.02 & 0.05 & & 11 & 8 & 26 & 11 \\
\hline \multirow[t]{2}{*}{ 8. Potential slack } & 0.00 & 0.01 & 0.03 & 0.01 & -0.02 & 0.03 & 0.01 & & 8680 & 8934 & 2106 \\
\hline & 0.03 & 0.02 & 0.02 & 0.03 & 0.05 & 0.07 & 0.04 & & 7 & 10 & 3 \\
\hline \multirow[t]{2}{*}{ 9. Bankruptcy } & 0.02 & 0.04 & 0.02 & 0.06 & 0.21 & -0.05 & 0.05 & -0.14 & & 23438 & 18203 \\
\hline & 0.03 & 0.04 & 0.05 & 0.08 & 0.10 & 0.05 & 0.03 & 0.08 & & 8 & 3 \\
\hline \multirow[t]{2}{*}{ 10. Organizational size } & 0.15 & 0.06 & -0.04 & 0.09 & 0.04 & -0.05 & -0.04 & -0.01 & -0.03 & & 28273 \\
\hline & 0.05 & 0.02 & 0.02 & 0.03 & 0.02 & 0.06 & 0.02 & 0.03 & 0.04 & & 20 \\
\hline \multirow[t]{2}{*}{ 11. Organizational age } & 0.03 & 0.00 & -0.01 & 0.05 & 0.01 & 0.06 & -0.03 & 0.05 & 0.05 & 0.19 & \\
\hline & 0.04 & 0.04 & 0.04 & 0.02 & 0.02 & 0.03 & 0.02 & 0.04 & 0.06 & 0.04 & \\
\hline
\end{tabular}

Note: Cells below the diagonal contain mean effect sizes and standard errors. Cells above the diagonal contain the total number of firms $(N)$ and number of effect sizes $(k)$. 
Table 3

Meta-Analyses and Heterogeneity Statistics - All Types of Responsiveness

\begin{tabular}{lrrrrrrrrrrr}
\hline Variable & $k$ & $\mathrm{r}$ & $\mathrm{CI}_{\mathrm{lb}}$ & $\mathrm{CI}_{\mathrm{ub}}$ & $p$ & $\mathrm{CR}_{\mathrm{lb}}$ & $\mathrm{CR}_{\mathrm{ub}}$ & $\mathrm{Q}_{\text {statistic }}$ & $\mathrm{Q}_{\mathrm{p}}$ & $\mathrm{I}^{2}$ & $\mathrm{Tau}^{2}$ \\
\hline $\mathrm{P}<\mathrm{HA}$ & 59 & -0.03 & -0.06 & 0.00 & 0.054 & -0.20 & 0.14 & 353.47 & $<0.001$ & 83.59 & 0.01 \\
& & & & & & & & & & & \\
$\mathrm{P}>\mathrm{HA}$ & 57 & -0.02 & -0.04 & 0.01 & 0.172 & -0.15 & 0.12 & 217.50 & $<0.001$ & 74.25 & 0.00 \\
& & & & & & & & & & & \\
$\mathrm{P}<\mathrm{SA}$ & 71 & -0.01 & -0.03 & 0.02 & 0.452 & -0.16 & 0.14 & 343.78 & $<0.001$ & 79.64 & 0.01 \\
& & & & & & & & & & & \\
$\mathrm{P}>$ SA & 70 & 0.00 & -0.03 & 0.02 & 0.899 & -0.14 & 0.14 & 313.89 & $<0.001$ & 78.02 & 0.01
\end{tabular}

Note: $k=$ number of studies, $r=$ mean correlation, $C I_{l b}=$ lower bound of $95 \%$ confidence interval, $C I_{u b}=$ upper bound of $95 \%$ confidence interval, $C R_{l b}=$ lower bound of $95 \%$ credibility interval, $C R_{u b}=$ upper bound of $95 \%$ credibility interval, $Q_{\text {statistic }}=$ Cochran's homogeneity test statistic, $Q_{p}=$ corresponding p-value of Q-statistic, $I^{2}=$ scale-free index of heterogeneity, $t a u^{2}=$ betweenstudy variance. 
Table 4

MASEM Meta-Analytic Results

\begin{tabular}{|c|c|c|c|c|c|c|c|c|c|c|c|c|}
\hline \multirow[b]{2}{*}{ Variable } & \multicolumn{4}{|c|}{ All Types of Resposiveness } & \multicolumn{4}{|c|}{ Organizational Search } & \multicolumn{4}{|c|}{ Organizational Change } \\
\hline & Beta & $\mathrm{CI}_{\mathrm{lb}}$ & $\mathrm{CI}_{\mathrm{ub}}$ & $p$ & Beta & $\mathrm{CI}_{\mathrm{lb}}$ & $\mathrm{CI}_{\mathrm{ub}}$ & $p$ & Beta & $\mathrm{CI}_{\mathrm{lb}}$ & $\mathrm{CI}_{\mathrm{ub}}$ & $p$ \\
\hline $\mathrm{P}<\mathrm{HA}$ & -0.04 & -0.05 & -0.02 & 0.000 & -0.11 & -0.15 & -0.07 & 0.000 & -0.02 & -0.04 & 0.00 & 0.034 \\
\hline $\mathrm{P}>\mathrm{HA}$ & 0.00 & -0.02 & 0.01 & 0.747 & 0.05 & 0.02 & 0.09 & 0.001 & -0.01 & -0.03 & 0.00 & 0.133 \\
\hline $\mathrm{P}<\mathrm{SA}$ & -0.01 & -0.03 & 0.01 & 0.214 & 0.01 & -0.03 & 0.05 & 0.772 & -0.01 & -0.03 & 0.01 & 0.184 \\
\hline $\mathrm{P}>\mathrm{SA}$ & -0.01 & -0.02 & 0.01 & 0.354 & 0.00 & -0.03 & 0.04 & 0.923 & 0.01 & -0.01 & 0.03 & 0.480 \\
\hline Absorbed slack & -0.02 & -0.03 & -0.01 & 0.006 & -0.01 & -0.05 & 0.02 & 0.498 & -0.03 & -0.05 & -0.01 & 0.000 \\
\hline Unabsorbed slack & 0.01 & 0.00 & 0.03 & 0.047 & 0.00 & -0.03 & 0.04 & 0.806 & 0.02 & 0.01 & 0.04 & 0.008 \\
\hline Potential slack & 0.01 & 0.00 & 0.02 & 0.144 & -0.09 & -0.12 & -0.05 & 0.000 & 0.05 & 0.03 & 0.07 & 0.000 \\
\hline Distance to bankruptcy & 0.03 & 0.02 & 0.04 & 0.000 & 0.13 & 0.10 & 0.17 & 0.000 & -0.04 & -0.06 & -0.02 & 0.000 \\
\hline Organizational size & 0.16 & 0.14 & 0.17 & 0.000 & 0.08 & 0.04 & 0.11 & 0.000 & 0.19 & 0.17 & 0.21 & 0.000 \\
\hline Organizational age & 0.00 & -0.01 & 0.02 & 0.707 & -0.06 & -0.09 & -0.02 & 0.001 & 0.03 & 0.01 & 0.05 & 0.000 \\
\hline$N$ (sample size) & 19145 & & & & 3520 & & & & 14136 & & & \\
\hline$K$ (number of effects) & 1416 & & & & 361 & & & & 1055 & & & \\
\hline$R^{2}$ & $2.71 \%$ & & & & $4.46 \%$ & & & & $4.25 \%$ & & & \\
\hline$\chi^{2}$ & 526.26 & & & & 160.54 & & & & 613.85 & & & \\
\hline
\end{tabular}

Note $:$ Beta $=$ regression coefficient, $\mathrm{CI}_{\mathrm{lb}}=$ lower bound of $95 \%$ confidence interval, $\mathrm{CI}_{\mathrm{ub}}=$ upper bound of $95 \%$ confidence interval, $S E=$ standard error, $p=p$-value. The explained variance for performance below the aspiration level for all types of responsiveness is $2.63 \%$ and the explained variance for the performance above the aspiration level for all types of responsiveness is $2.01 \%$. 
Table 5

MARA Meta-Analytic Results

\begin{tabular}{lccrrrrrrrrrrr}
\hline & \multicolumn{3}{c}{ P $<$ HA } & \multicolumn{3}{c}{ P $>$ HA } & \multicolumn{3}{c}{ P S SA } & \multicolumn{3}{c}{ P SA } \\
\hline Variable & Beta & SE & $p$ & Beta & SE & $p$ & Beta & SE & $p$ & Beta & SE & $p$ \\
\hline Constant & -0.15 & 0.02 & 0.000 & -0.11 & 0.02 & 0.000 & -0.21 & 0.03 & 0.000 & -0.11 & 0.03 & 0.001 \\
Private & 0.13 & 0.02 & 0.000 & 0.06 & 0.03 & 0.045 & 0.17 & 0.02 & 0.000 & 0.11 & 0.04 & 0.006 \\
Mixed & 0.04 & 0.02 & 0.075 & -0.07 & 0.03 & 0.045 & 0.15 & 0.03 & 0.000 & 0.16 & 0.04 & 0.001 \\
Non-financial & -0.01 & 0.01 & 0.268 & -0.07 & 0.01 & 0.000 & 0.08 & 0.03 & 0.011 & 0.07 & 0.04 & 0.083 \\
Firm age & 0.00 & 0.00 & 0.000 & 0.00 & 0.00 & 0.464 & 0.00 & 0.00 & 0.001 & 0.00 & 0.00 & 0.505 \\
Service & -0.03 & 0.02 & 0.090 & -0.10 & 0.03 & 0.003 & -0.03 & 0.03 & 0.220 & -0.03 & 0.04 & 0.392 \\
High-tech & 0.05 & 0.02 & 0.027 & -0.06 & 0.03 & 0.050 & 0.03 & 0.04 & 0.458 & -0.01 & 0.04 & 0.777 \\
Change & 0.08 & 0.02 & 0.000 & 0.14 & 0.02 & 0.000 & 0.07 & 0.02 & 0.001 & 0.03 & 0.02 & 0.194 \\
\hline$K$ & 31 & & & 30 & & & 38 & & & 37 & &
\end{tabular}

Note $:$ Beta $=$ regression coefficient, $\mathrm{CI}_{\mathrm{lb}}=$ lower bound of $95 \%$ confidence interval, $\mathrm{CI}_{\mathrm{ub}}=$ upper bound of $95 \%$ confidence interval, $S E=$ standard error, $p=$ p-value, $K=$ number of studies. 
Table 6

MASEM Results - High-tech industries

\begin{tabular}{lrrrrrrrr}
\hline & \multicolumn{3}{c}{ Model 1 } & \multicolumn{5}{c}{ Model 2 } \\
\hline Variable & Beta & $\mathrm{CI}_{\mathrm{lb}}$ & $\mathrm{CI}_{\mathrm{ub}}$ & $p$ & Beta & $\mathrm{CI}_{\mathrm{lb}}$ & $\mathrm{CI}_{\mathrm{ub}}$ & $p$ \\
\hline $\mathrm{P}<\mathrm{HA}$ & -0.03 & -0.14 & 0.08 & 0.603 & 0.00 & -0.04 & 0.04 & 0.929 \\
$\mathrm{P}>\mathrm{HA}$ & -0.07 & -0.20 & 0.06 & 0.284 & -0.07 & -0.12 & -0.03 & 0.002 \\
$\mathrm{P}<\mathrm{SA}$ & -0.05 & -0.17 & 0.07 & 0.390 & -0.07 & -0.11 & -0.03 & 0.001 \\
$\mathrm{P}>$ SA & 0.11 & -0.04 & 0.25 & 0.141 & 0.06 & 0.01 & 0.11 & 0.026 \\
Absorbed slack & -0.10 & -0.20 & 0.00 & 0.054 & -0.19 & -0.24 & -0.15 & 0.000 \\
Unabsorbed slack & 0.03 & -0.07 & 0.13 & 0.531 & 0.09 & 0.05 & 0.13 & 0.000 \\
Potential slack & -0.15 & -0.27 & -0.03 & 0.013 & -0.04 & -0.08 & 0.00 & 0.054 \\
Distance to bankruptcy & 0.08 & -0.02 & 0.19 & 0.129 & 0.13 & 0.09 & 0.17 & 0.000 \\
Organizational size & 0.18 & 0.07 & 0.28 & 0.002 & 0.27 & 0.22 & 0.31 & 0.000 \\
Organizational age & 0.05 & -0.05 & 0.15 & 0.316 & 0.00 & -0.04 & 0.04 & 0.888 \\
\hline$N$ (sample size) & 383 & & & & 2821 & & & \\
$K$ (number of effects) & 399 & & & & 399 & & & \\
$R^{2}$ & $7.85 \%$ & & & & & & &
\end{tabular}

Note: Model 1 uses the number of firms as input for the average sample size, Model 2 uses the number of observations as input for the average sample size. Beta = regression coefficient, $S E=$ standard error, $p=$ p-value 